\title{
Reductive Adsorption of Chromium(VI) with Activated Carbon
}

\author{
Anh Viet HoAnG ${ }^{1}$, Ya Wen $\mathrm{CHEN}^{2}$, Ya-Fen WANG ${ }^{2}$, Syouhei NishiHAMA ${ }^{1 *}$, and Kazuharu YoshizUKA ${ }^{1}$ \\ ${ }^{1}$ Department of Chemical Engineering, The University of Kitakyushu, Hibikino 1-1, Kitakyushu 808-0135, Japan \\ ${ }^{2}$ Department of Environmental Engineering, Chung Yuan Christian University, 200 Chung Pei Road, Chung Li District, Taoyuan \\ City, Taiwan 32023, R.O.C.
}

\begin{abstract}
Reductive adsorption of chromium (Cr) has been investigated, employing coal-based activated carbon with batchwise study. The adsorption was carried out by varying parameters such as $\mathrm{pH}$ of the aqueous solution and contact time. $\mathrm{Cr}$ (III) was hardly adsorbed on activated carbon, and it was precipitated at high $\mathrm{pH}$ region. High adsorption amounts of $\mathrm{Cr}(\mathrm{VI})$ was obtained at $\mathrm{pH}$ range $4.5-5.5$. In the adsorption process, reduction of $\mathrm{Cr}(\mathrm{VI})$ to $\mathrm{Cr}(\mathrm{III})$ was occurred at especially acidic $\mathrm{pH}$ region, and thus most of $\mathrm{Cr}$ remained in the aqueous solution in this $\mathrm{pH}$ region was $\mathrm{Cr}(\mathrm{III})$.
\end{abstract}

\section{Introduction}

Increasing attention is being given to human health hazards caused by the contamination of toxic heavy metals in the water environment and their accumulation in human body has been a serious health problem. Chromium $(\mathrm{Cr})$ is one of the contaminants which exists in hexavalent form $(\mathrm{Cr}(\mathrm{VI}))$ and trivalent form $(\mathrm{Cr}(\mathrm{III}))$, and $\mathrm{Cr}(\mathrm{VI})$ possesses significantly higher level of toxic than $\mathrm{Cr}(\mathrm{III})$. $\mathrm{Cr}$ (VI) poisoning in human being is harmful to the nervous system, bleed, live and bone (Chen et al., 2018). $\mathrm{Cr}$ and its compounds are widely used in various industries field such as electroplating, metal polishing and leather tanning (Beheshti et al., 2016). The maximum level concentration in wastewater is reported at $0.05 \mathrm{mg} / \mathrm{L}$ for $\mathrm{Cr}(\mathrm{VI})$ and $5 \mathrm{mg} / \mathrm{L}$ for $\mathrm{Cr}(\mathrm{III})$ (Ali et al., 2015; Chen et al., 2018). Hence, removal of $\mathrm{Cr}(\mathrm{VI})$ has received more and more attention.

Presently, several methods and technologies have been adopted to remove $\mathrm{Cr}(\mathrm{VI})$ from water, such as ion exchange (Ali et al., 2015), adsorption (Kobya et al., 2004), membrane technology (Çengeloğlu et al., 2003), and reduction (Chen et al., 2018). Among available methods, adsorption is one of preferable method for removal of $\mathrm{Cr}(\mathrm{VI})$ in aquatic environment. In addition, reduction of $\mathrm{Cr}(\mathrm{VI})$ to $\mathrm{Cr}(\mathrm{III})$ is effective for detoxication, since the toxic of $\mathrm{Cr}(\mathrm{III})$ is much lower than that of $\mathrm{Cr}(\mathrm{VI})$ 100 times (Chen et al., 2018). Various of materials, such as iron compounds (Ali et al., 2015), ion exchange resin (Pehlivan and Cetin, 2009), activated carbon (Chen et al., 2018; Kobya et al., 2004), magnetic chitosan (Zheng et al., 2018) and nickel oxide (Behnajady and Bimeghdar, 2014), were also reported. Among these materials, activated carbon offers an attractive and low-cost option for the removal of contaminants from water environment. Several researches on adsorption of $\mathrm{Cr}(\mathrm{VI})$ with activated carbon have been reported in literature (Kobya et al.,
2004; Nethaji et al., 2013). However, reduction of Cr(VI) to $\mathrm{Cr}$ (III) with activated carbon during the adsorption processing was scarcely investigated.

In the present work, the reductive adsorption of $\mathrm{Cr}(\mathrm{VI})$ with coal-based activated carbon was investigated.

\section{Experiment}

\subsection{Material}

Coal-based activated carbon, M010, was supplied by Mitsubishi Chemical Co. (Tokyo, Japan). $\mathrm{Cr}\left(\mathrm{NO}_{3}\right)_{3} \cdot 9 \mathrm{H}_{2} \mathrm{O}$ was supplied from Alfa Aesar (Ward Hill, USA). $\mathrm{CrO}_{3}$ and all other reagents were supplied by Wako Pure Chemical Industries (Osaka, Japan) as analytical grade reagents. The activated carbon was characterized by a zeta potential analyzer (ELSZ-1000, Otsuka Electronics Co., Ltd.).

\subsection{Experiment}

Aqueous feed solutions were prepared by dissolving $\mathrm{CrO}_{3}$ or $\mathrm{Cr}\left(\mathrm{NO}_{3}\right)_{3} \cdot 9 \mathrm{H}_{2} \mathrm{O}$ in deionized water. Batchwise experiment was carried out by shaking mixture of M010 (50 $\mathrm{mg}$, activated carbon particle size, $0.5-1.0 \mathrm{~mm}$ ) and aqueous feed solution $(10 \mathrm{~mL})$ at $298 \mathrm{~K}$. Cr concentration was fixed at $1.0 \mathrm{mmol} / \mathrm{L}$, and $\mathrm{pH}$ values were adjusted by adding amount of $\mathrm{NaOH}$ or $\mathrm{H}_{2} \mathrm{SO}_{4}$. After filtration, total $\mathrm{Cr}$ concentration ([Cr $\left.]_{\text {total }}\right)$ was determined by an inductively coupled plasma atomic emission spectrometer (ICP-AES, Shimadzu ICPE-9000), while $\mathrm{Cr}(\mathrm{VI})$ concentration was analyzed by UV/vis spectrophotometer (UV-660, JASCO) at $540 \mathrm{~nm}$ after reacting with 1,5diphenylcarbazide (DPC) indicator (Çengeloğlu et al., 2003; Wiryawan et al., 2018). Cr(III) concentration was determined by $[\mathrm{Cr}(\mathrm{III})]=[\mathrm{Cr}]_{\text {total }}-[\mathrm{Cr}(\mathrm{VI})]$. The adsorption

* Corresponding author: nishihama@kitakyu-u.ac.jp 
amount of $\mathrm{Cr}$ on $\mathrm{M} 010, q(\mathrm{mmol} / \mathrm{g})$, was determined by equation:

$$
q=\frac{\left([\mathrm{Cr}]_{\mathrm{feed}}-[\mathrm{Cr}]_{\mathrm{total}}\right) \cdot V}{m}
$$

where $[\mathrm{Cr}]_{\text {feed }}$ and $[\mathrm{Cr}]_{\text {total }}$ are initial and equilibrium concentrations of $\mathrm{Cr}$ in aqueous solution [mmol/L], $V$ is the volume of solution [L], and $m$ is weight of adsorbent [g].

\section{Results and Discussion}

\subsection{Characterization of activated carbon M010}

Characterization of M010 was carried out in a previous work (Yamaguchi et al., 2010). Pore volume and specific surface area were determined by $\mathrm{N}_{2}$ adsorption as $0.531 \mathrm{~cm}^{3} / \mathrm{g}$ and $1390 \mathrm{~m}^{2} / \mathrm{g}$. Amount of surface functional group of M010 was analyzed by Boehm titration as 0.190 $\mathrm{mmol} / \mathrm{g}$ phenolic and $0.040 \mathrm{mmol} / \mathrm{g}$ basic. Figure 1 shows the zeta potentials of M010 in aqueous solution at various of $\mathrm{pH}$. The isoelectric point (IP) was determined as 5.95.

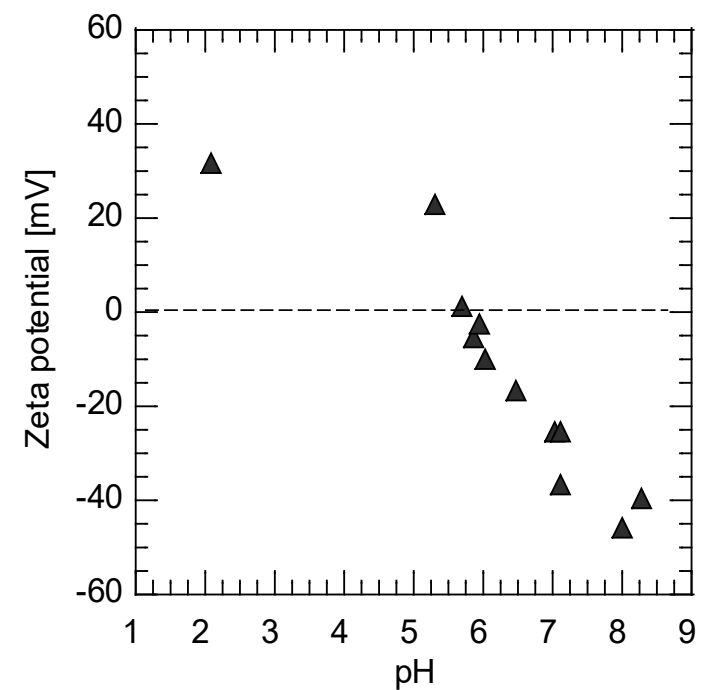

Figure 1. The zeta potential of M010 in aqueous solution with various $\mathrm{pH}$.

\subsection{Effect of $\mathrm{pH}$ on reductive adsorption of $\mathrm{Cr}(\mathrm{VI})$}

The $\mathrm{pH}$ of the aqueous solution plays an important role to determine the adsorption performance, since species distribution of $\mathrm{Cr}$ in an aqueous solution is strongly affected by $\mathrm{pH}$ of aqueous solution. Figure 2 shows the effect of $\mathrm{pH}$ on adsorption amount of $\mathrm{Cr}(\mathrm{VI})$ on M010. The adsorption amount is increased in acidic $\mathrm{pH}$ region, and then is decreased in $\mathrm{pH}>6.0$. The adsorption amounts were sharply depended by $\mathrm{pH}$, and high adsorption amount of $0.22 \mathrm{mmol} / \mathrm{g}$ was obtained in $\mathrm{pH}_{\mathrm{eq}}=4.5-5.5$. The different adsorption amount could be explained that the electrostatic attraction between adsorbate $\left(\mathrm{Cr}_{2} \mathrm{O}_{7}{ }^{2-}\right.$ and $\left.\mathrm{CrO}_{4}{ }^{2-}\right)$ and surface of adsorbent were occurred below pH $5.95(\mathrm{IP}=5.95)$.

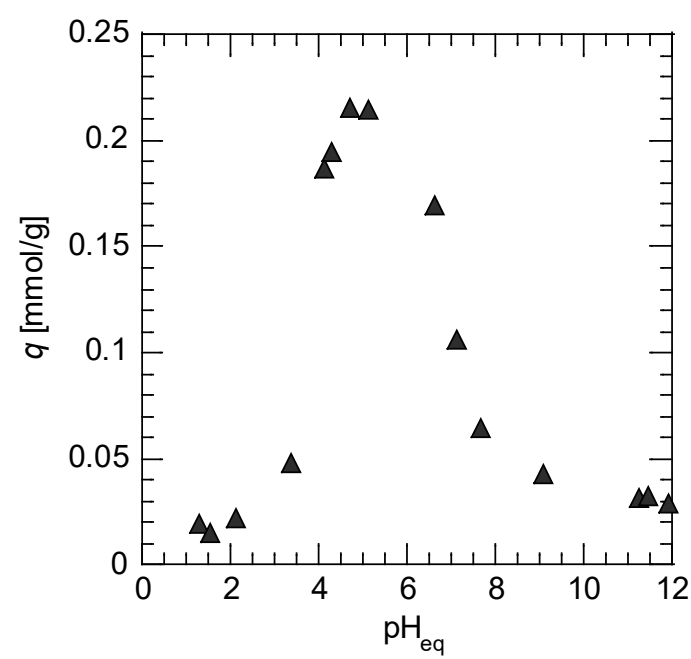

Figure 2. Effect of $\mathrm{pH}$ on adsorption of $\mathrm{Cr}(\mathrm{VI})$ with $\mathrm{M} 010$.

Figure 3 shows the percentage of $\mathrm{Cr}$ species remained in aqueous solution, after adsorption. Most of $\mathrm{Cr}$ remained in solution at $\mathrm{pH}<4.0$ was $\mathrm{Cr}(\mathrm{III})$, while that at $\mathrm{pH}>4.0$ was $\mathrm{Cr}(\mathrm{VI})$. Reduction of $\mathrm{Cr}(\mathrm{VI})$ in aqueous solution was proceeded as follows Eqs. (2) and (3) (Bard et al., 1985; Milazzo et al., 1978):

$$
\begin{aligned}
& \mathrm{Cr}_{2} \mathrm{O}_{7}^{2-}+14 \mathrm{H}^{+}+6 \mathrm{e}^{-} \leftrightarrow 2 \mathrm{Cr}^{3+}+7 \mathrm{H}_{2} \mathrm{O} \\
& \mathrm{CrO}_{4}^{2-}+4 \mathrm{H}_{2} \mathrm{O}+3 \mathrm{e}^{-} \leftrightarrow \mathrm{Cr}(\mathrm{OH})_{4}^{-}+4 \mathrm{OH}^{-}
\end{aligned}
$$$$
\text { (in } 1 \mathrm{~mol} / \mathrm{L} \mathrm{NaOH} \text { ) }
$$

In acidic $\mathrm{pH}$ region, $\mathrm{Cr}(\mathrm{III})$ reduced by $\mathrm{M} 010$ could be released into aqueous solution, and then adsorption reduction was cycled. In addition, $\mathrm{Cr}$ (III) reduced and remained in solution could be precipitated (Bernardo et al., 2009) and adsorbed by M010. Figure 4 shows the effect of $\mathrm{pH}$ on the precipitation percentage of $\mathrm{Cr}$ (III). $\mathrm{Cr}$ (III) was started precipitation from $\mathrm{pH}=4.5$, and the most of $\mathrm{Cr}$ (III) was precipitated in $\mathrm{pH}$ range $5.0-10.0$.

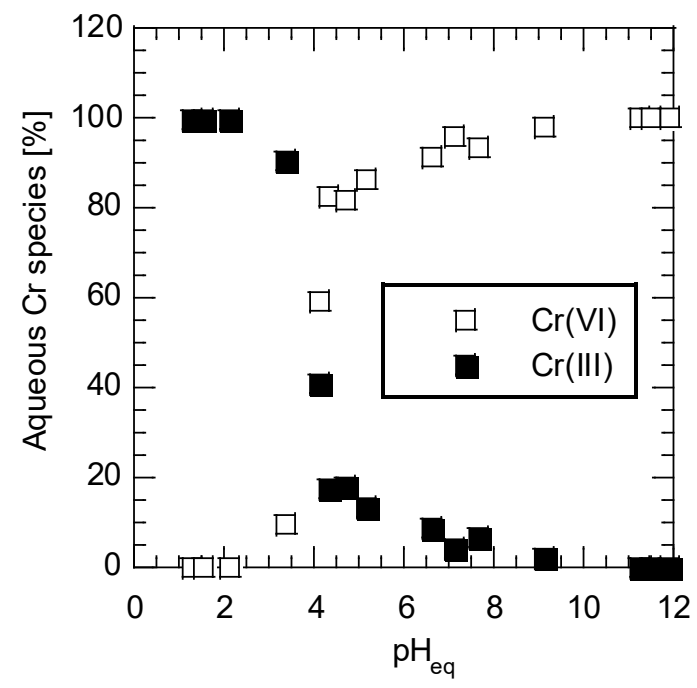

Figure 3. Cr species remained in aqueous solution. 


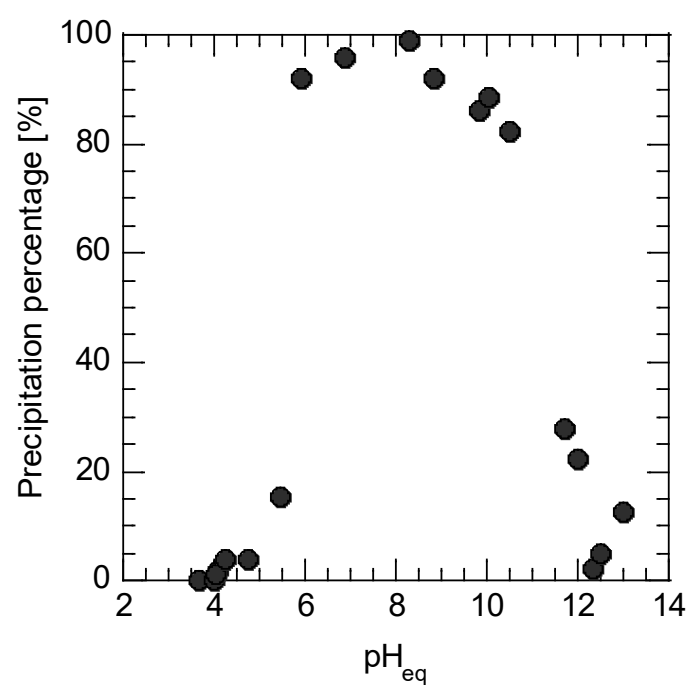

Figure 4. Effect of $\mathrm{pH}$ on precipitation percentage of $\mathrm{Cr}(\mathrm{III})$.

Figure 5 shows the effect of $\mathrm{pH}$ on adsorption of $\mathrm{Cr}(\mathrm{III})$ at $\mathrm{pH}<4.5$. $\mathrm{Cr}$ (III) was hardly adsorbed on $\mathrm{M} 010$ in acidic $\mathrm{pH}$ region. This is because the surface of M010 has positive charge in $\mathrm{pH}<5.95$, while $\mathrm{Cr}$ (III) exists as
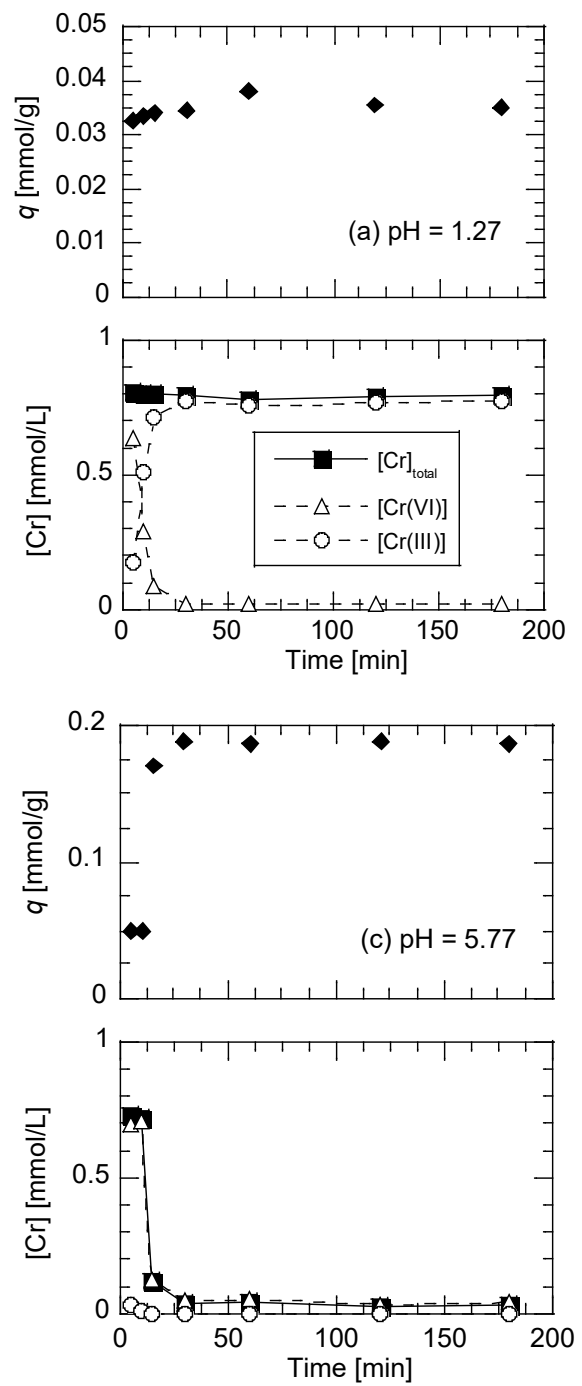

Figure 6. Time-course and variation of $\mathrm{pH}$ on reductive adsorption of $\mathrm{Cr}(\mathrm{VI})$ on $\mathrm{M} 010$. $\mathrm{Cr}(\mathrm{III})$ in aqueous solution.
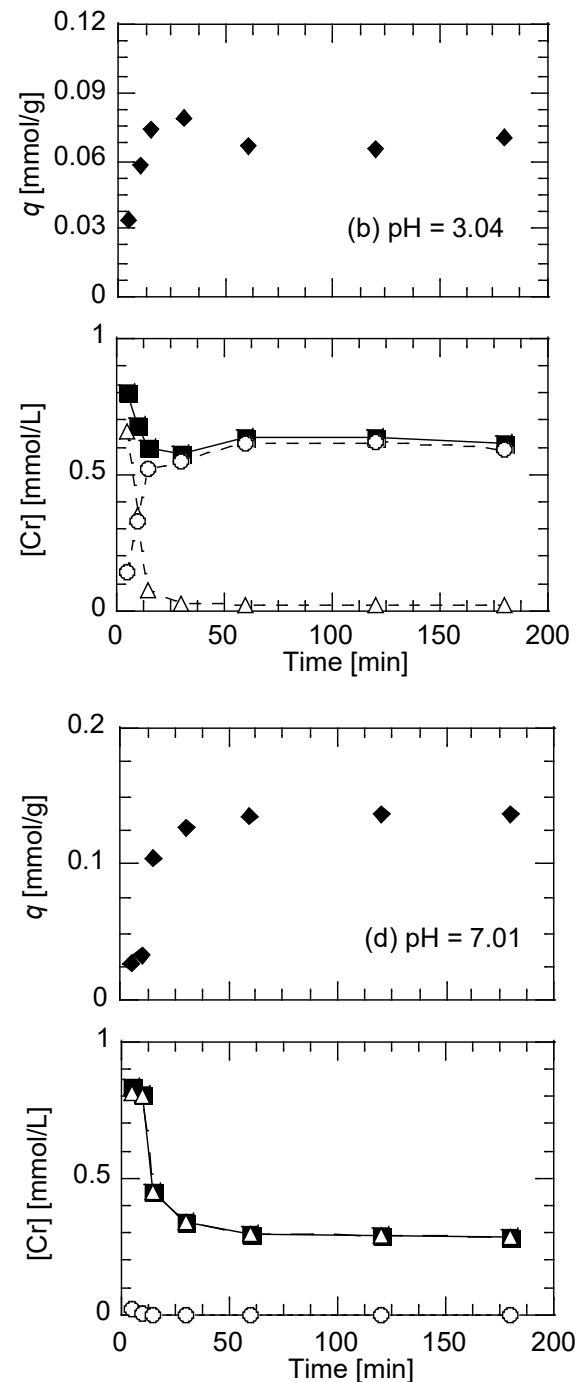
adsorption of $\mathrm{Cr}(\mathrm{VI})$ could be described as the adsorption of $\mathrm{Cr}(\mathrm{VI})$ - reduction of $\mathrm{Cr}(\mathrm{VI})$ to $\mathrm{Cr}(\mathrm{III})$ - release of

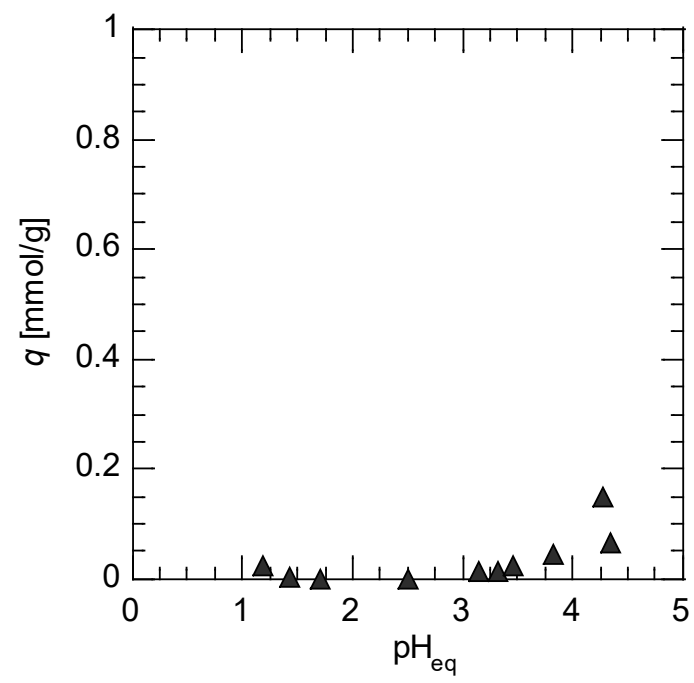

Figure 5. Effect of $\mathrm{pH}$ on adsorption of $\mathrm{Cr}(\mathrm{III})$. 


\subsection{Time-course with variation of $\mathrm{pH}$ in reductive adsorption of $\mathrm{Cr}(\mathrm{VI})$}

Time-course variation of the reductive adsorption of $\mathrm{Cr}(\mathrm{VI})$ with variation of $\mathrm{pH}$ values was investigated. Figure 6 shows time-course variation of adsorption amount of $\mathrm{Cr}$ on the M010, together with the concentration of $\mathrm{Cr}(\mathrm{VI})$ and $\mathrm{Cr}(\mathrm{III})$ in the aqueous solution. The reductive adsorption was achieved to be equilibrium within $30 \mathrm{~min}$ in all $\mathrm{pH}$ regions investigated. In the cases at acidic $\mathrm{pH}$ region $(\mathrm{pH}=1.27$ and 3.04), the concentration of $\mathrm{Cr}$ (III) in the aqueous solution was therefore increased with operation time, while the concentration of $\mathrm{Cr}(\mathrm{VI})$ was decreased. On the other hand, the reduction hardly occurs at higher $\mathrm{pH}$ region $(\mathrm{pH}=$ 5.77 and 7.01) and thus the concentration of $\mathrm{Cr}(\mathrm{III})$ in the aqueous solution was almost zero.

The detail information on the kinetics of the reductive adsorption of $\mathrm{Cr}(\mathrm{VI})$ on $\mathrm{M} 010$ should be investigated in the future, to reveal the mechanism of the reductive adsorption system.

\section{Conclusion}

Reductive adsorption of $\mathrm{Cr}(\mathrm{VI})$ with activated carbon M010 was investigated using batchwise study. The reductive adsorption of $\mathrm{Cr}(\mathrm{VI})$ was equilibrium at $30 \mathrm{~min}$. Reductive adsorption of $\mathrm{Cr}(\mathrm{VI})$ was sharply affected by the $\mathrm{pH}$ of aqueous solution. High adsorption amount obtained within $\mathrm{pH} 4.0-5.5$, while reduction of $\mathrm{Cr}(\mathrm{VI})$ was occurred in aqueous solution in acidic region.

\section{References}

Ali, S. W., M. L. Mirza, and T. M. Bhatti; "Removal of $\mathrm{Cr}(\mathrm{VI})$ Using Iron Nanoparticles Supported on Porous Cation-exchange Resin," Hydrometallurgy, 157, 82-89 (2015)

Bard, A.J., R. Parsons, and J. Jordan; Standard Potentials in Aqueous Solution, pp. 453-484, M. Dekker, New York, U.S.A. (1985)

Beheshti, H., M. Irani, L. Hosseini, A. Rahimi, and M. Aliabadi; "Removal of Cr (VI) from Aqueous Solutions Using Chitosan/MWCNT/ $\mathrm{Fe}_{3} \mathrm{O}_{4}$ Composite NanofibersBatch and Column Studies," Chem. Eng. J., 284, 557-564 (2016)

Behnajady, M. A. and S. Bimeghdar; "Synthesis of Mesoporous NiO Nanoparticles and Their Application in the Adsorption of Cr(VI)," Chem. Eng. J., 239, 105-113 (2014)

Bernardo, G.-R. R., R.-M. J. Rene, and A.-D. la T. Ma. Catalina; "Chromium (III) Uptake by Agro-waste Biosorbents: Chemical Characterization, SorptionDesorption Studies, and Mechanism," J. Hazard. Mater., 170, 845-854 (2009)

Çengeloğlu, Y., A. Tor, E. Kir, and M. Ersöz; “Transport of Hexavalent Chromium through Anion-exchange Membranes," Desalination, 154, 239-246 (2003)

Chen, Y., D. An, S. Sun, J. Gao, and L. Qian; "Reduction and Removal of Chromium VI in Water by Powdered Activated Carbon," Materials, 11, 269 (2018).

Kobya, M.; "Adsorption, Kinetic and Equilibrium Studies of Cr(VI) by Hazelnut Shell Activated Carbon," Adsorpt. Sci. Technol, 22, 51-64 (2004)

Milazzo, G., S. Caroli, V.K. Sharma; Tables of Standard Electrode Potentials, John Wiley \& Sons, Chichester, U.S.A. (1978)

Nethaji, S., A. Sivasamy, and A. B. Mandal; "Preparation and Characterization of Corn Cob Activated Carbon Coated with Nano-sized Magnetite Particles for the Removal of Cr(VI)," Bioresour. Technol., 134, 94-100 (2013)

Pehlivan, E. and S. Cetin; "Sorption of $\mathrm{Cr}(\mathrm{VI})$ Ions on Two Lewatit-anion Exchange Resins and Their Quantitative Determination Using UV-visible Spectrophotometer," J. Hazard. Mater., 163, 448-453 (2009)

Wiryawan, A., R. Suntari, Z. Kusuma, R. Retnowati, and R. Y. P. Burhan; "Method of Analysis for Determination of the Chromium (Cr) Species in Water Samples by Spectrophotometry with Diphenylcarbazide," Int. J. ChemTech Res., 16(01), 391-406 (2018)

Yamaguchi, A., S. Nishihama, and K. Yoshizuka; "Seperation of Tetramethyl Amonium Hydroxide in Waste Water with Ion Exchange Using Activated Carbon Prepared by Bamboo," J. Ion Exch., 24, 375-381 (2010)

Zheng, C., H. Zheng, Y. Wang, Y. Wang, W. Qu, Q. An, and Y. Liu; "Synthesis of Novel Modified Magnetic Chitosan Particles and Their Adsorption Performance Toward Cr(VI)," Bioresour. Technol., 267, 1-8 (2018) 